\title{
The nature of the electrophysiological disorder in adynamia episodica
}

\author{
A. J. McCOM-AS, K. MROŻEK ${ }^{1}$, AND W. G. BRADLEY \\ From the Department of Physiology, University of Newcastle upon Tyne, \\ and Muscular Dystrophy Research Laboratories, Newcastle General Hospital
}

In 1934 Biemond and Daniels first showed that the serum potassium level fell during paralytic episodes in patients with familial periodic paralysis. Subsequently a normokalaemic form of the disease was recognized by Tyler, Stevens, Gunn, and Perkoff (1951), while more recently a hyperkalaemic variety was described by Helweg-Larsen, Hauge, and Sagild (1955). This last type of periodic paralysis was given the name adynamia episodica hereditaria by Gamstorp (1956).

In view of the functional relationship between electrical potential and potassium conductance across cell membranes (Hodgkin, 1958), it has been widely anticipated that intracellular recording from muscle fibres in these various conditions might prove a valuable analytical approach. Up to the present time such studies have been carried out on patients with hypokalaemic familial periodic paralysis by Shy, Wanko, Rowley, and Engel (1961), Riecker, and Bolte (1966), and Creutzfeldt, Abbott, Fowler, and Pearson (1963), while the last authors have also investigated a single patient with the hyperkalaemic variety. Recently we have had an opportunity to make intracellular recordings, between attacks, in a further four patients with hyperkalaemic paralysis and in one with the normokalaemic syndrome. The results to be described indicate that the hyper- and normokalaemic varieties appear to be functionally similar in so far as the resting membrane potential is reduced in both. In addition we have employed intracellular stimulation to investigate the electrical properties of the fibre membranes more fully; the results obtained have been considered in relation to the genesis of the paralytic episodes.

\section{METHODS}

PATIENTS The five patients were volunteers to whom the nature of the investigation had been explained beforehand.

ADYNAMIA EPISODICA HEREDITARIA Three of the patients investigated were siblings and the fourth (R.S.) was a cousin.

'Present address: Department of Neurology, Medical School, Warsaw.
L.W. was an 18-year-old female shop assistant; she $\frac{\overline{\bar{F}}}{\overline{\frac{\sigma}{5}}}$ had a history of paralytic episodes involving the arms and $\stackrel{\Phi}{\Phi}$ legs on both sides from the age of 5 .

$A . W$. was a 24 -year-old male decorator with a 12-year ${ }^{0}$ history of paralytic attacks affecting the legs only.

$J . W$. was a 31-year-old male tool setter who had sufferedfrom intermittent paralysis of his arms and legs for $\vec{\omega}$ approximately 20 years.

R.S. was a 27-year-old male welder who had a 10-year history of paralytic episodes involving all four limbs.

NORMOKALAEMIC PERIODIC PARALYSIS G.G. was a $24 . \overrightarrow{\mathrm{c}}$ year-old civil servant with a history of intermitte paralysis of all four limbs since the age of 2 ; he ha्ष $\infty$ previously been investigated (Case 2) by Poskanzer aff음 Kerr (1961).

A more detailed account of the histories of the patients, together with the results of various biochemical and histological investigations, will be reported separatedy by one of us (Bradley, 1968).

IINTRACELLULAR STIMULATION AND RECORDING The left rectus femoris muscle was investigated in all five patients using the in vivo technique described by McComas, Mrożek, Gardner-Medwin, and Stanton (1968). In three patients (L.W., A.W., and J.W.) local anaesthesia was $\bar{\partial}$ achieved with a femoral nerve block, while in the remaining two patients (G.G. and R.S.) a general $\underset{\mathbb{Q}}{\mathbb{2}}$

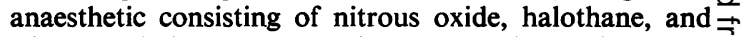
trichloroethylene was employed. At the end of the 음 recording session a specimen of muscle was removed for histological examination.

STATISTICAL TREATMENT OF RESULTS Throughout the text the means have been expressed with the corresponding $\frac{7}{0}$ standard errors. The ' $t$ ' test was used to calculate the $\bar{\sigma}$ significance of differences between means.

\section{RESULTS}

RESTING MEMBRANE POTENTIALS Satisfactory impalements were made in a total of 130 fibres in the four patients with adynamia episodica and in 53 fibres in the patient with normokalaemic paralysis; the pooled $\mathrm{N}$ results are shown in Fig. 1 while the mean value for $\mathrm{N}$ each patient has been presented in Table I. In every N్ 


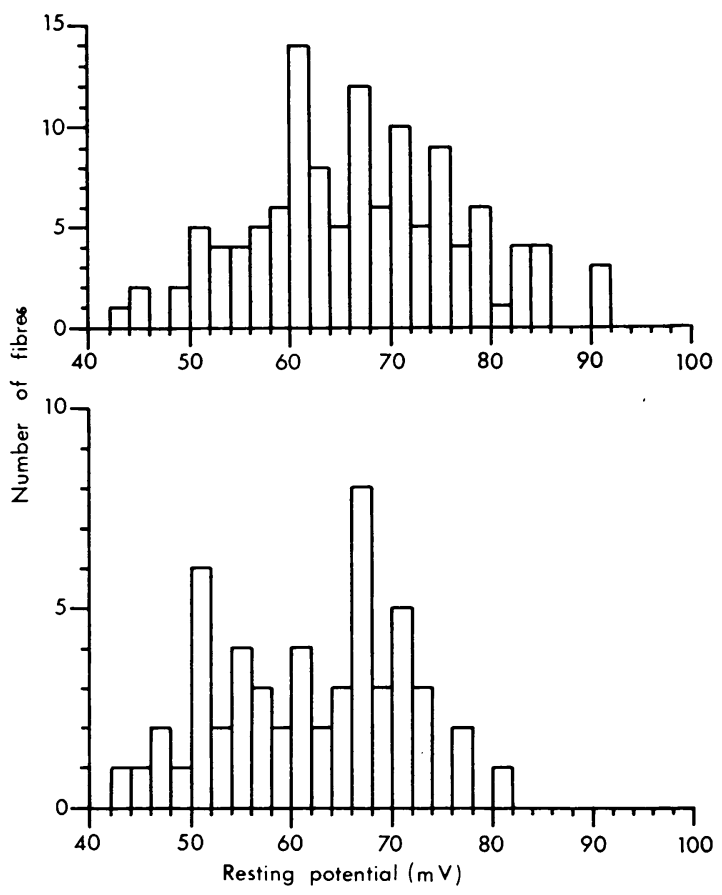

FIG. 1. Resting membrane potentials in four patients with adynamia episodica (upper) and in one patient with normokalaemic periodic paralysis (lower histogram); mean potentials were $66.3 \pm 0.9 \mathrm{mV}$ (130 fibres) and $61.3 \pm$ $1 \cdot 3 \mathrm{mV}$ (53 fibres) respectively. All measurements were made between paralytic episodes.

patient the mean resting potential was found to be significantly lower $(P=<0.001)$ than the value of $83.6 \pm 0.5 \mathrm{mV}$ reported for control subjects by McComas et al. (1968).

In one patient (A.W.) an unsuccessful attempt was made to induce an attack of paralysis with an intravenous injection of potassium chloride solution. The serum potassium level, measured five minutes after injection, was $5.6 \mathrm{~m}$-equiv/l. and was the same as the initial value. The mean resting potential of 10 fibres investigated within 20 minutes of injection was $69.4 \pm 3.1 \mathrm{mV}$ and was virtually identical with the mean during the control period $(69.5 \pm 2.8 \mathrm{mV}$, 20 fibres). In none of the subjects investigated could myotonic activity be detected, nor had this been observed during previous examination with concentric needle electrodes.

INTRACELLULAR STIMULATION The results of intracellular stimulation were most interesting since, although it was easy to produce electrotonic potentials (Fig. 2A), it proved extremely difficult to initiate
TABLE I

MEAN MUSCLE FIBRE MEMBRANE POTENTIALS IN FOUR PATIENTS WITH ADYNAMIA EPISODICA AND ONE PATIENT WITH NORMOKALAEMIC PARALYSIS

\begin{tabular}{llll} 
Patient & Diagnosis & $\begin{array}{l}\text { Resting potential } \\
\text { Mean } \pm \text { S.E. } \\
(\mathrm{mV})\end{array}$ & $\begin{array}{l}\text { Fibres } \\
(\mathrm{no} .)\end{array}$ \\
\hline A.W. & Adynamia & $69.5 \pm 2 \cdot 8$ & 20 \\
A.W. & Adynamia & $69 \cdot 4 \pm 3 \cdot 1^{*}$ & $10^{*}$ \\
L.W. & Adynamia & $66.0 \pm 2 \cdot 0$ & 30 \\
J.W. & Adynamia & $61.6 \pm 2 \cdot 8$ & 22 \\
R.S. & Adynamia & $67.1 \pm 1 \cdot 1$ & 58 \\
G.G. & Normokalaemic paralysis & $61.3 \pm 1.3$ & 53
\end{tabular}

* Results obtained following injection of $\mathrm{KCl}$ solution (see text).

TABLE II

COMPARISON OF RESTING POTENTIALS (R.P.) MEMBRANE TIME CONSTANTS $\left(T_{m}\right)$ AND INPUT RESISTANCES $\left(R_{i n}\right)$ IN ADYNAMIA EPISODICA, NORMOKALAEMIC PERIODIC PARALYSIS AND CONTROL SUBJECTS (MCCOMAS et al., 1968)

\begin{tabular}{|c|c|c|c|c|}
\hline & $\begin{array}{l}\text { Subjects } \\
\text { (no.) }\end{array}$ & ts $\underset{(m V)}{R . P .}$ & $\begin{array}{l}T_{\mathrm{m}} \\
(\text { msec })\end{array}$ & $\stackrel{R \text { in }}{\left(\times 10^{5} \Omega\right)}$ \\
\hline Controls & 3 & $\begin{array}{l}83.6 \pm 0.5 \\
(134)\end{array}$ & $\begin{array}{l}6 \cdot 3 \pm 0.4 \\
(19)\end{array}$ & $\begin{array}{l}2.7 \pm 0.2 \\
(19)\end{array}$ \\
\hline Adynamia & 4 & $\begin{array}{l}66 \cdot 3 \pm 0 \cdot 9 * \\
(130)\end{array}$ & $\begin{array}{l}4 \cdot 2 \pm 0 \cdot 1^{*} \\
(23)\end{array}$ & $\begin{array}{l}1.9 \pm 0.1^{*} \\
(23)\end{array}$ \\
\hline $\begin{array}{l}\text { Normokalaemic } \\
\text { paralysis }\end{array}$ & 1 & $\begin{array}{l}61 \cdot 3 \pm 1 \cdot 3^{*} \\
(53)\end{array}$ & $\begin{array}{l}3 \cdot 8 \pm 0 \cdot 2^{*} \\
(30)\end{array}$ & $\begin{array}{l}2 \cdot 3 \pm 0.4 \\
(30)\end{array}$ \\
\hline
\end{tabular}

Values expressed as means \pm S.E.; numbers of fibres given in brackets. *Mean values significantly different from control at $\boldsymbol{P}=<0.001$ level.

full-sized action potentials. From the electrotonic potentials it was possible to determine the membrane time constants and input resistances of the fibres (McComas et al., 1968). In Figs. 3 and 4 the individual values of these two parameters have been presented separately for adynamia episodica and normokalaemic periodic paralysis; in Table II the mean values have been compared with those of the control fibres investigated by McComas et al. (1968). Table II shows that there was a significant reduction of membrane time constant and input resistance in adynamia episodica and of membrane time constant in normokalaemic periodic paralysis; the input resistance was also reduced in the latter condition, but not significantly so.

The inability to initiate action potentials was surprising, since none of the patients exhibited paralysis at the time of investigation. Nevertheless no such difficulty has been experienced in all the 'non-paralytic' muscles we have so far investigated (in threecontrol subjects, two patients with dystrophia myotonica, and one patient with a neuropathy). Thus in only 22 of the 153 'non-paralytic' fibres tested $(14.4 \%)$ could action potentials not be found and these failures have been tentatively attributed to fibre damage at the time of stimulation.

The minimum current required to excite 'non- 


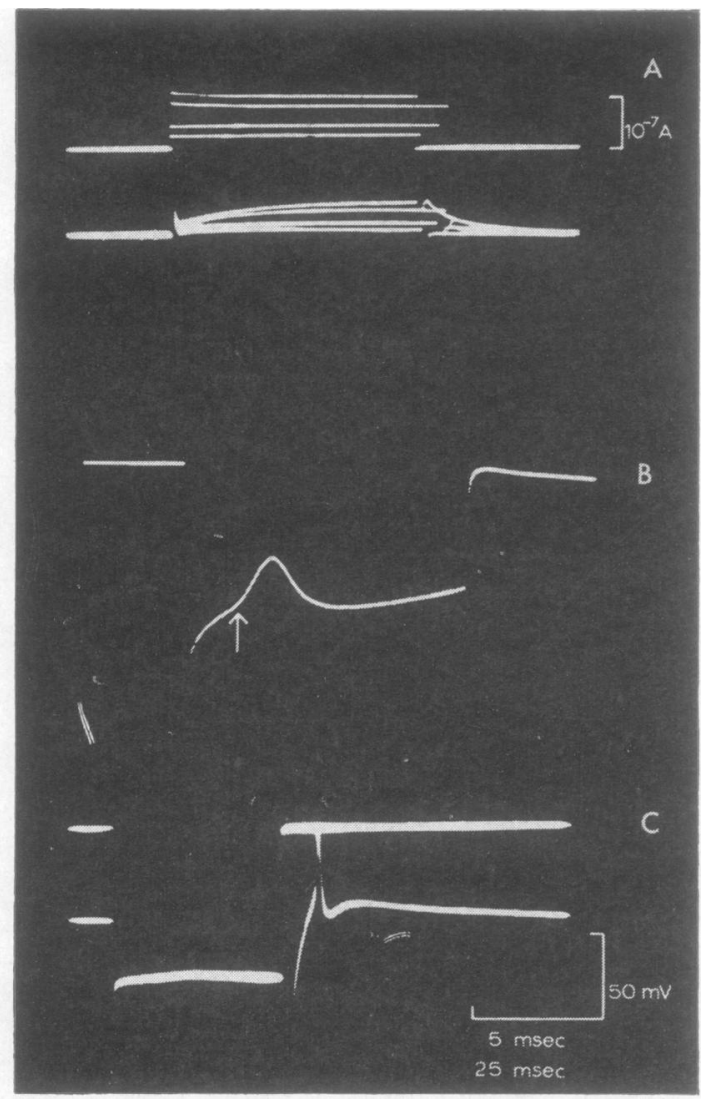

FIG. 2. Responses of three muscle fibres in adynamia episodica to intracellular stimulation. $A$, fibre exhibiting electrotonic potentials only (resting potential, $50 \mathrm{~m} \mathrm{~V}$; input resistance, $2.2 \times 10^{5} \Omega$; time constant, $3.5 \mathrm{msec}$ approximately. Photograph retouched. $B$, fibre developing a 'local' response (arrowed; see text) in response to a depolarizing current of $8.2 \times 10^{-8} \mathrm{~A}$; imbalance of the Wheatstone bridge has caused the onset of the response to be displaced from resting potential-that is, downwards on photograph. $C$, fibre responding to 'break' excitation; resting potential $54 \mathrm{mV}$. At the end of a 30 msec hyperpolarizing pulse the fibre fires an action potential of $46 \mathrm{mV}$ amplitude. In $A$ and $C$ the upper traces display the magnitudes of the current pulses. The horizontal bar represents $5 \mathrm{msec}$ for $A$ and $B$, and 25 msec for $C$.

paralytic' fibres could not be accurately measured since the mechanical instability of the recording system restricted the time available for examining individual fibres in detail; in the majority of fibres, however, the current threshold was less than $5 \times$ $10^{-8} \mathrm{~A}$. In adynamia episodica, on the other hand, stimuli of this magnitude usually elicited electrotonic potentials only (Fig. 2A) or, less commonly, local responses. Larger pulses (up to $10^{-7} \mathrm{~A}$ ) evoked
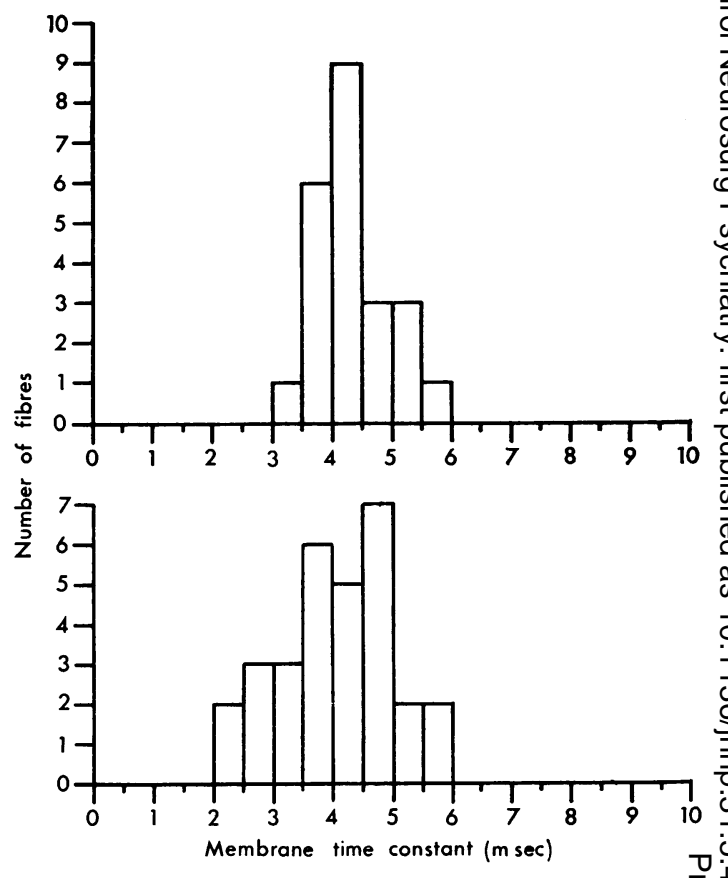

FIG. 3. Membrane time constants in adynamia episodie (upper) and normokalaemic periodic paralysis (lowera: $\circ$ mean values were $4 \cdot 2 \pm 0 \cdot 1$ msec (23 fibres) and $3 \cdot 8$ $0.2 \mathrm{msec}$ (30 fibres) respectively.

potentials which may still have been local response or alternatively were small action potentialsexample, Fig. 2B; however, on no occasion did the exceed $40 \mathrm{mV}$. In one patient (R.S.) hyperpolarizing. ${ }^{\circ}$ pulses were applied through the recording electrodes and under these circumstances 'break' excitation (Beránek, 1964) could be readily obtained (Fig. 2C).

In assessing the significance of these results in adynamia episodica account must be taken of the $\stackrel{\varnothing}{\perp}$ reduced input resistances of fibres (see above); thus, $\overrightarrow{\vec{F}}$ compared with normal fibres, a larger current is 3 necessary to produce a given depolarization. In addition, however, it appears that the critical membrane depolarization is raised in adynamia episodica. For example, depolarizations of 12-20 mV were usually ineffective in initiating local or propa-: gated potentials, whereas in control fibres the largest 3 . critical membrane depolarization measured was $17 \mathrm{mV}$ and the mean value was $11.8 \pm 0.4 \mathrm{mV}$ (McComas et al., 1968).

\section{DISCUSSION}

The finding of reduced membrane potentials in four or cases of adynamia episodica is in agreement with $N$ the observations of Creutzfeldt et al. (1963) on a N 


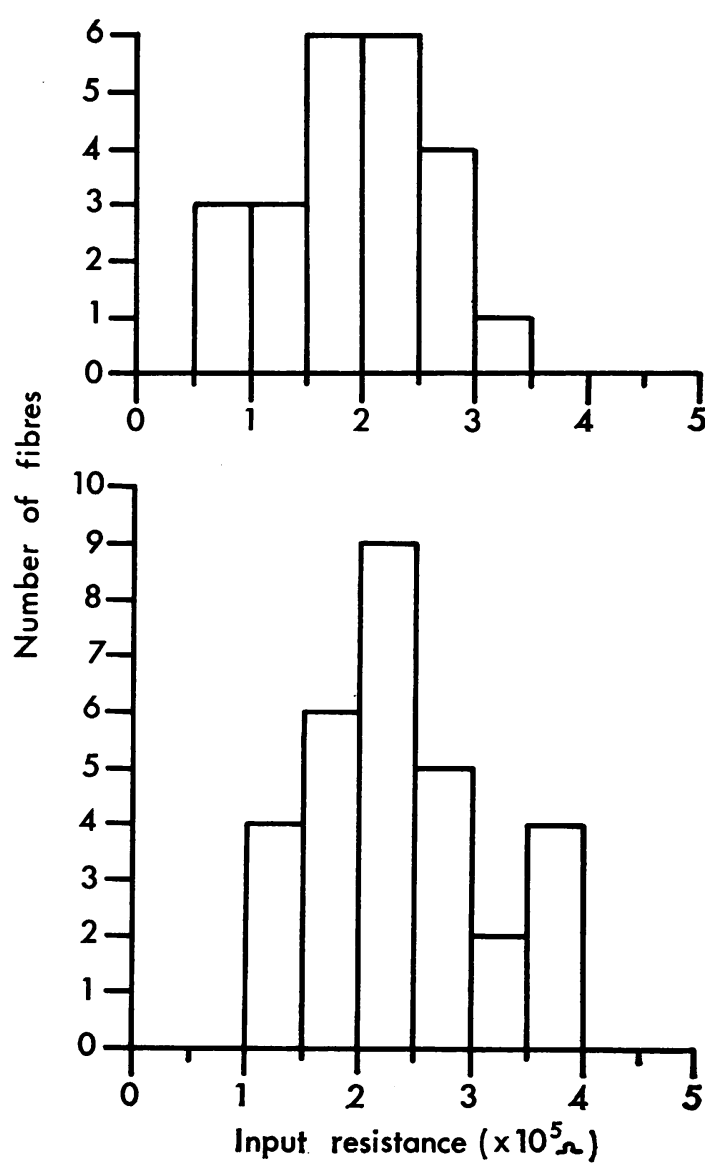

FIG. 4. Input resistances of fibres in adynamia episodica (upper) and normokalaemic periodic paralysis (lower); mean values were $1.9 \pm 0.1 \times 10^{5} \Omega(23$ fibres $)$ and $2.3 \pm$ $0.4 \times 10^{5} \Omega(30$ fibres $)$ respectively.

single patient with this condition. Furthermore, measurements of resting potential and membrane time constant have revealed a functional similarity between muscle fibres in adynamia episodica and those in normokalaemic periodic paralysis.

The most likely explanation of the low resting potentials in these two conditions is that there has been an increase in the ratio of sodium to potassium permeabilities of the fibre membrane, since

$$
\mathrm{E}_{\mathrm{m}}=\frac{\mathrm{RT}}{\mathrm{F}} \log _{e} \frac{[\mathrm{K}]_{0}+\mathrm{b}[\mathrm{Na}]_{0}}{[\mathrm{~K}]_{i}+\mathrm{b}[\mathrm{Na}]_{i}}
$$

(where $E_{m}$ is the resting potential, $R$ is the universal gas constant, $T$ is the absolute temperature, and $F$ is the Faraday constant) $[\mathrm{K}]_{0},[\mathrm{Na}]_{0}$ and $[\mathrm{K}]_{i},[\mathrm{Na}]_{i}$ indicate the concentrations of potassium and sodium on the outside and inside of the cell respectively; b signifies the membrane permeability for sodium relative to that for potassium (Hodgkin, 1958).

An alteration in the sodium : potassium permeability ratio could occur under two circumstances. First, there could be a rise in sodium permeability, as suggested by Creutzfeldt et al. (1963) for adynamia episodica. Alternatively, there could be a fall in potassium permeability, as occurs in denervated muscle (Lüllmann, 1960). In distinguishing between these two possibilities the measurements of membrane time constant and input resistance are crucial. Thus if the sodium permeability increases while that of potassium remains unchanged, then the total permeability of the fibre membrane should be elevated. The findings of a fall in input resistance and of a reduction in time constant both suggest that this is indeed the case.

A rise in sodium permeability, apart from lowering the resting potential, would have important consequences for the distribution of electrolytes across the muscle fibre membrane; it would cause the Donnan equilibrium to be disturbed and the passive efflux of potassium to increase. In theory the increased efflux of potassium could be offset by active transport; however, the rise in serum potassium which occurs during paralytic episodes in adynamia episodica suggests that the inward potassium pumping mechanism cannot gear its activity to a sufficiently high level.

It was hoped that the design of the present study might also provide clues concerning the cause of the paralytic episodes. It is known that these episodes are associated with a reduction in the electrical activity developed by the muscle during willed effort (Buchthal, Engbaek, and Gamstorp, 1958) and it is possible that such a reduction might occur under two sets of circumstances. The first possibility is that propagation of impulses along the fibre membrane is interfered with. This condition might arise if the surface membrane was sufficiently stretched by dilated sarcoplasmic cisternae, such as have been described in hypokalaemic familial periodic paralysis by Shy et al. (1961) and in adynamia episodica by Bradley (1968).

The second possibility is that there is a generalized defect of the membrane which could prevent the initiation of impulses at the neuromuscular junction or perhaps further along the fibre. This hypothesis has been investigated in the present study by the technique of intracellular stimulation with simultaneous recording. The most striking finding was the repeated failure to excite fibres with stimuli adequate for control muscles. Since the muscles were not paralysed at the time of experiment it follows that the critical membrane depolarizations must have 
been higher than the depolarizations induced in the present study.

It is, of course, possible that the results were misleading due to fibre damage inflicted by the micro-electrode; this explanation would, in turn, imply that in adynamia episodica the fibres exhibited a fragility of the membrane not found in normal muscles. However, since there were no other indications of fibre damage, we are inclined towards the view that the inefficacy of stimulation reflected a true physiological abnormality of the muscle fibre membrane.

Our suggestion is that in adynamia episodica the muscle fibre membrane displays refractoriness-that is, the resting depolarization of the muscle fibre membrane inactivates an appreciable fraction of the regenerative sodium conductance mechanism responsible for the action potential (Hodgkin and Huxley, 1952). In these circumstances a larger depolarization than normal would be required to harness the remainder of the regenerative system. Furthermore, a paralytic attack would result if the depolarization progressed so as to inactivate the regenerative sodium conductance mechanism completely. An additional prediction of this hypothesis is that 'break' excitation should be normally effective; thus hyperpolarization of the muscle would restore the regenerative sodium conductance mechanism and permit excitation at the end of the stimulus pulse. Our experimental observations, though limited in number, are in agreement with this prediction.

Nevertheless, there are several other features which remain puzzling-for example, in dystrophia myotonica low resting potentials were also encountered by McComas and Mrożek (1968) and yet intracellular stimulation was effective. At the present time, however, we believe that the explanation offered has the virtue of unifying the various experimental findings; furthermore, it may serve to provide a useful working hypothesis for the electrophysiological defect in adynamia episodica.

\section{SUMMARY}

An electrophysiological examination of single muscle fibres has been made in four patients with adynamia episodica hereditaria and in one patient with normokalaemic periodic paralysis.

In all five patients the resting membrane potentials of muscle fibres were abnormally low; in addition the membrane time-constants and input resistances were reduced.
Attempts to stimulate individual fibres with depolarizing pulses were unsuccessful, presumably due to a rise in critical membrane depolarization.

The results have been interpreted as evidence of an? increase in the sodium permeability of the muscle fibre membrane in adynamia episodica and normo-s kalaemic periodic paralysis.

Special thanks are due to the five patients and to Dr. J. N $\underset{\gtrless}{\vec{Z}}$ Walton, Dr. J. B. Foster, and Dr. D. N. S. Kerr for permission to study them. We also wish to acknowledgess generous help received from Dr. D. Gardner-Medwin,o Dr. H. B. Ghosh, Mr. W. H. Stanton, Mr. C. A. Wallace,

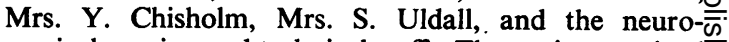
surgical nursing and technical staffs. The projest received financial support from the Medical Research Council, $\varrho$ the Muscular Dystrophy Group of Great Britain, and the Muscular Dystrophy Associations of America, Inc. $\vec{\nabla}$

\section{REFERENCES}

Beránek, R. (1964). Intracellular stimulation myography in man. Electroenceph. clin. Neurophysiol., 16, 301-304.

Biemond, A., and Daniels, A. P. (1934). Familial periodic paralysisc and its transition into spinal muscular atrophy. Brain, 57, 91-108.

Bradley, W. G. (1968). Adynamia episodica hereditaria. A clinied pathological and electrophysiological study of a family. 9 n preparation.

Buchthal, F., Engbaek, L., and Gamstorp, I. (1958). Paresis $\bigcap_{\text {rdd }}$ 응 hyperexcitability in adynamia episodica hereditaria. Neuroløg (Minneap.), 8, 347-351.

Creutzfeldt, O. D., Abbott, B. C., Fowler, W. M., and Pearson, C. (1963). Muscle membrane potentials in episodic adynanta. Electroenceph. clin. Neurophysiol., 15, 508-519.

Gamstorp, I. (1956). Adynamia episodica hereditaria. Acta paedkat. 믄 (Uppsala), 45, (Supp. No. 108), 1-126.

Helweg-Larsen, H. F., Hauge, M., and Sagild, U. (1955). Hereditât transient muscular paralysis in Denmark: genetic aspects: family periodic paralysis and family periodic adynamia. Acta genet. (Basel), 5, 263-281.

Hodgkin, A. L. (1958). Ionic movements and electrical activity inO giant nerve fibres. Proc. roy. Soc. B., 148, 1-37.

on sodium conductance in the giant axon of Loligo. J. Physiol. ָి (Lond.), 116, 497-506.

Lüllman, H. (1960). Uber die Ursache spontaner Fibrillationen denervierter Skeletmuskulatur. Klin. Wschr., 38, 1169-1171.

McComas, A. J., and Mrozek, K. (1968). The electrical properties of muscle fibre membranes in dystrophia myotonica and myotonia-

- congenita. J. Neurol. Neurosurg. Psychiat., 31, 441-447. Electrical properties of muscle fibre membranes in man. Ibid., 31, 434.440.

Poskanzer, D. C., and Kerr, D. N. S. (1961). A third type of periodic paralysis with normokalemia and favourable response to sodium chloride. Amer. $J$. Med., 31, 328-342.

Riecker, G., and Bolte, H. D. (1966). Membranpotentiale einzelner Skeletmuskelzellen bei hypokaliamischer periodischer Muskel $?$ paralyse. Klin. Wschr., 44, 804-807.

Shy, G. M., Wanko, T., Rowley, P. T., and Engel, A. G. (1961).음 Studies in familial periodic paralysis. Exp. neurol., 3, 53-121.

Tyler, F. H., Stevens, F. E., Gunn, F. D., and Perkoff, G. T. (1951).0 Studies in disorders of muscle: VII. clinical manifestations and inheritance of a type of periodic paralysis without hypo- $D$ potassemia. J. clin. Invest., 30, 492-502. 